\title{
Characterization of scrotal involvement in children and adolescents with IgA vasculitis
}

\author{
Izabel M. Buscatti ${ }^{1}$, Henrique M. Abrão ${ }^{2}$, Katia Kozu', Victor L. S. Marques ${ }^{1}$, Roberta C. Gomes ${ }^{1}$, \\ Adriana M. E. Sallum ${ }^{1}$ and Clovis A. Silva ${ }^{3^{*}}$ (D)
}

\begin{abstract}
Objective: To characterize scrotal involvement in children and adolescents with IgA vasculitis.

Methods: A cross-sectional retrospective study included $296 \mathrm{lgA}$ vasculitis (EULAR/PRINTO/PRES criteria) patients, 150/296 (51\%) were males and assessed by demographic/clinical/laboratory and treatments. Scrotal involvement was defined by the presence of scrotal edema and/or pain/tenderness in physical examination and/or testicular Doppler ultrasound abnormalities.
\end{abstract}

Results: Scrotal involvement was observed in 28/150 (19\%) IgA vasculitis patients. This complication was evidenced at IgA vasculitis diagnosis in 27/28 (96\%). Acute recurrent scrotal involvement was observed in 2/150 (1\%) and none had chronic subtype. Further analysis of patients with scrotal involvement at first episode $(n=27)$ compared to those without this complication $(n=122)$ revealed that the median age at diagnosis $[4.0(2.0-12)$ vs. $6(1.3-13)$ years, $p=0.249$ ] was similar in both groups. The frequency of elevated serum IgA was significantly lower in IgA vasculitis patients with scrotal involvement versus without this manifestation ( $18 \%$ vs. $57 \%, p=0.017$ ), whereas glucocorticoid ( $93 \%$ vs. $49 \%, p<0.0001)$ and ranitidine use $(63 \%$ vs. $30 \%, p=0.003)$ were significantly higher in the former group.

Conclusions: The scrotal involvement occurred in almost one fifth of IgA vasculitis patients and was commonly evidenced as acute subtype at diagnosis. Scrotal signs/symptoms improved after a prompt use of glucocorticoid and was associated with low frequency of elevated IgA serum levels.

Keywords: IgA vasculitis, Henoch-Schönlein purpura, Scrotal vasculitis, Children, Glucocorticoid, Testicular ultrasound

\section{Background}

Immunoglobulin A (IgA) vasculitis previously known as Henoch-Schönlein purpura (HSP), is the most frequent systemic vasculitis of small vessels with IgA dominant immune complexes deposits [1-7]. The most common manifestations at diagnosis are cutaneous, articular, gastrointestinal and renal $[1,2,4]$.

Scrotal involvement in children and adolescents with IgA vasculitis is generally acute, resulting in scrotal edema, pain and/or tenderness in physical examination [1, 3, 7-11]. Doppler testicular ultrasound may help to confirm the scrotal involvement and to exclude testicular torsion $[7,12]$.

\footnotetext{
* Correspondence: clovis.silva@hc.fm.usp.br

${ }^{3}$ Pediatric Rheumatology Unit, Children's Institute, Hospital das Clinicas HCFMUSP, Faculdade de Medicina, Universidade de Sao Paulo, SP, Av. Dr. Eneas Carvalho Aguiar, 647 - Cerqueira César, São Paulo, SP 05403-000, Brazil Full list of author information is available at the end of the article
}

In 2010, validated classification criteria for IgA vasculitis were established and proposed by European League Against Rheumatism (EULAR), Paediatric Rheumatology International Trials Organisation (PRINTO) and Paediatric Rheumatology European Society (PRES) [13]. Data of scrotal involvement in IgA vasculitis patients are limited due to the small representation of this complication in previous case reports or case series [1, 3, 5, 8-12] precluding an accurate analysis of associated factors and outcomes in patients with and without this complication, particularly using the EULAR/PRINTO/PRESS IgA vasculitis classification criteria [9].

Therefore, the objective of the present study was to characterize scrotal involvement in children and adolescents with IgA vasculitis, and to evaluate the possible association of demographic data, clinical manifestations,

(C) The Author(s). 2018 Open Access This article is distributed under the terms of the Creative Commons Attribution 4.0 International License (http://creativecommons.org/licenses/by/4.0/), which permits unrestricted use, distribution, and 
laboratorial abnormalities and treatments in patients with and without scrotal involvement.

\section{Methods}

Data from 322 children and adolescents with IgA vasculitis followed at the Pediatric Rheumatology Department of our University Hospital during a 32-year period (January 1983 to December 2015) were retrospectively evaluated. Twenty-six patients were excluded due to incomplete data in medical charts. All 296 patients fulfilled IgA vasculitis validated EULAR/PRINTO/PRES classification criteria [13]. Out of them, 150/296 (51\%) IgA vasculitis patients were males and were assessed by demographic data, clinical manifestations, laboratory exams and treatments. The Ethics Committee of the University Hospital approved this study. Informed consent was obtained from all participants and their legal guardians.

Scrotal involvement was defined by the presence of scrotal edema and/or pain/tenderness in physical examination and/or testicular Doppler ultrasound abnormalities $[3,9]$. Patients with only petechiae or purpuric rash on scrotum were excluded [9]. This manifestation was characterized by three subtypes: acute scrotal involvement, acute recurrent (new presence of scrotal signs/ symptoms and/or testicular Doppler ultrasound abnormalities after total recovery) [1] and chronic (presence of scrotal signs/symptoms and/or testicular Doppler ultrasound abnormalities with more than 3 months duration) [14].

The demographic data included: age at diagnosis, disease duration and body mass index (BMI). BMI was defined as weight in kilograms divided by the square of the body height $\left(\mathrm{m}^{2}\right)$.

Recurrent purpura/petechiae was considered as new skin lesions after total recovery and persistent purpura/ petechiae, as cutaneous lesions persisting for more than one month [1]. Arthritis was defined by joint swelling or joint pain with limitation on motion. Arthralgia was characterized by joint pain without joint edema or limitation on motion [13]. Recurrent arthritis was considered as new joint inflammation after total recovery [1].

Abdominal pain was determined as colicky and diffuse pain with acute onset. Severe abdominal pain was defined as the presence of at least one of them: abdominal angina, bowel intussusception and gastrointestinal bleeding. Recurrence was defined as new abdominal pain after complete resolution [1]. Abdominal Doppler ultrasound was performed to evaluate severe abdominal involvement [1].

Renal involvement was defined by proteinuria $>0.1 \mathrm{~g} / \mathrm{m}^{2} /$ day and/or hematuria $>5$ red blood cells/high power field or red blood cells casts in the urinary sediment. Nephrotic syndrome was characterized by edema, serum albumin $<2.5 \mathrm{~g} / \mathrm{L}$ and proteinuria $>1 \mathrm{~g} / \mathrm{m}^{2} /$ day [1]. High blood pressure was defined as systolic and/ or diastolic blood pressures $\geq 95$ th percentile for gender, age and height on $\geq 3$ occasions [15]. Acute kidney injury was determined by sudden increase in serum creatinine above $2 \mathrm{mg} / \mathrm{dl}$ [16] or by modified RIFLE (Risk, Injury, Failure, Loss of kidney function and End-stage kidney disease) criteria [17]. Chronic renal disease was defined as structural or functional abnormalities of the kidney for $\geq 3$ months (with or without decreased glomerular filtration rate) or glomerular filtration rate $<60 \mathrm{ml} / \mathrm{min} / 1.73 \mathrm{~m}^{2}$ for $\geq 3$ months [18]. Renal replacement therapies (hemodialysis, peritoneal dialysis and hemofiltration and renal transplantation) were also assessed. Renal biopsy was performed in all patients with severe nephritis and/or persistent renal alterations.

Neuropsychiatric involvement was defined as the presence of at least one neuropsychiatric manifestation, such as: headaches, seizures, hemiparesis, aphasia, cortical blindness and impaired consciousness [19].

Current treatment data were also recorded: prednisone/ prednisolone, intravenous methylprednisolone, ranitidine, intravenous immunoglobulin (IVIG), azathioprine, cyclosporine, intravenous cyclophosphamide (IVCYC) and plasmapheresis.

IgA vasculitis patients were also divided in two groups: with scrotal involvement at first episode and without scrotal involvement.

\section{Statistical analysis}

Results were presented as median (range) or mean \pm standard deviation for continuous variables and number (\%) for categorical variables. Mann Whitney or $t$ tests were used for comparing continuous variables to evaluate the differences between the two study groups (with scrotal involvement at first episode and without scrotal involvement). Fisher's exact test analyzed the differences for categorical variables. For all statistical tests the level of significance was defined as "p" value less than 0.05 .

\section{Results}

Scrotal involvement (scrotal edema with pain/tenderness) was observed in 28/150 (19\%) IgA vasculitis patients during disease course or follow up. Twenty-two of 150 patients (15\%) had unilateral involvement and 6/ 150 (4\%) had bilateral involvement. None of the patients had scrotal edema as the first sign/symptom of IgA vasculitis. This complication was evidenced at IgA vasculitis diagnosis in 27/28 (96\%). During follow-up, only one of them was diagnosed after one year of disease onset.

Regarding characterization of scrotal involvement subtypes in IgA vasculitis patients: acute subtype was observed in $26 / 150$ (17\%), acute recurrent subtype in $2 / 150$ (1\%) and none of them had chronic subtype. 
Thirteen patients underwent testicular Doppler ultrasound and the findings were described in Table 1. None of them had torsion, atrophy, tumor, necrosis and/or cysts on testicles. All of these 13 IgA vasculitis patients were followed-up, 11 of them remained without scrotal symptoms after total recovery and did not carry-out testicular Doppler ultrasound. Gastrointestinal involvement was observed in 7/13 (54\%) IgA vasculitis with testicular abnormalities on ultrasound examination. Two of 13 patients had acute recurrent involvement and were submitted to the second testicular Doppler ultrasound after total recovery, in one month and one year respectively, showing epididymitis-orchitis in both.

Regarding treatment, a short course of prednisolone/prednisone $(0.5-2.0 \mathrm{mg} / \mathrm{kg} /$ day $)$ was administered in $25 / 27$ (93\%), with resolution of scrotal signs/symptoms.

Further analysis of IgA vasculitis patients with scrotal involvement at first episode $(n=26)$ compared to those without this complication $(n=122)$ revealed that the median age at diagnosis $[4.0(2.0-12)$ vs. $6(1.3-13)$ years, $p=0.249]$ and purpura duration $[18.5(5-60)$ vs. $14(1-120)$ days, $p=0.101]$ were similar in both groups. The frequency of elevated serum IgA was significantly lower in IgA vasculitis patients with scrotal involvement versus without this manifestation ( $18 \%$ vs. $57 \%, p=0.017$ ), whereas glucocorticoid ( $93 \%$ vs. $49 \%, p<0.0001)$ and ranitidine use ( $63 \%$ vs. $30 \%, p=0.001)$ were significantly higher in the former group (Table 2).

The frequencies of persistent purpura/petechiae, arthritis/arthralgia, abdominal pain, nephritis and neuropsychiatric involvements were also similar in IgA vasculitis patients with scrotal involvement at first episode compared to those without this complication $(p>0.05)$ (Table 2). No differences were evidenced of gastrointestinal involvement in IgA vasculitis patients with scrotal involvement confirmed by testicular Doppler ultrasound compared to those with scrotal involvement that did underwent testicular Doppler ultrasound [7/13 (54\%) vs. $12 / 14$ (86\%), $p=0.103$ ].

None of IgA vasculitis patients had chronic renal disease, underwent renal replacement therapies or died.

\section{Discussion}

This study characterized scrotal involvement in IgA vasculitis patients using EULAR/PRINTO/PRES classification criteria [13]. This complication occurred in almost one fifth of male with IgA vasculitis and was commonly evidenced as acute subtype at diagnosis. Acute recurrent involvement was rarely observed. Scrotal signs/symptoms improved after a prompt use of glucocorticoid and was associated with low frequency of elevated IgA serum levels.

The strength of this study was inclusion of IgA vasculitis patients fulfilled the validated classification criteria [13] and use of standardized database to minimize bias. The characterization of scrotal involvement subtypes was also relevant, allowing to differentiate disease severity. However, the main weakness observed herein was the retrospective design, with potential missing data. We also did not evaluate the IgA glycosylation test [20].

The prevalence of acute scrotal involvement in IgA vasculitis patients observed in the present study was similar to other previous reports, ranging from 2 to $32 \%$ $[1,8,9,21,22]$. Bilateral involvement was observed in $20 \%$ of IgA vasculitis patients with scrotal involvement, as observed in Korean patients. Acute scrotal involvement as the first signs/symptoms of disease was also rarely been described [9].

One relevant point reported herein was the evaluation of severity according to scrotal involvements subtypes. Indeed, acute recurrent involvement was rarely evidenced in IgA vasculitis and none of them had complications with chronic scrotal pain and/or edema. These findings suggest a predominant acute and mild/moderate scrotal involvement.

IgA vasculitis is a primary vasculitis characterized by leukocytoclastic vasculitis involving the capillaries (mainly in skin, gastrointestinal and kidneys), with high levels of serum IgA (up to 40\%) and deposition of IgA immune complexes in these organs and systems [1, 23, 24]. Rare cases of IgA vasculitis patients also demonstrated deposition of IgA-containing immune complexes in the testicular vessels, supports the notion that testis is a target organ of this systemic vasculitis [25].

Interestingly, elevated serum IgA was lower in IgA vasculitis patients with scrotal involvement, and had similar frequencies of skin, articular, gastrointestinal and renal involvements [1]. These results may be related to different immunopathogenesis mechanisms in patients with autoimmune orchitis. Further studies will be necessary to clarify this point.

Table 1 Testicular Doppler ultrasound findings in 13 lgA vasculitis patients

\begin{tabular}{ll}
\hline Testicular Doppler ultrasound findings & $n=13$ \\
\hline Unilateral scrotal edema with soft tissue thickening, epidydimal swelling with normal blood flow & 3 (23) \\
Bilateral scrotal edema with soft tissue thickening, epidydimal swelling with normal blood flow & 3 (23) \\
Unilateral epidydimal swelling, hydrocele and scrotal wall thickening & 5 (39) \\
Bilateral epidydimal swelling, hydrocele and scrotal wall thickening & 2 (15)
\end{tabular}

Results are presented as $n(\%)$, hydrocele - fluids accumulation around testicle 
Table 2 Demographic data, clinical manifestations and treatments in patients with scrotal involvement at first episode compared to those without this condition in $149 \lg$ A vasculitis patients

\begin{tabular}{|c|c|c|}
\hline Variables at diagnosis, n (\%) & $\begin{array}{l}\text { With scrotal } \\
\text { involvement } \\
(n=27)\end{array}$ & $\begin{array}{l}\text { Without scrotal } \\
\text { involvement } \\
(n=122)\end{array}$ \\
\hline \multicolumn{3}{|l|}{ Demographic data } \\
\hline Age at diagnosis, years & $4.0(2.0-12.0)$ & $6.0(1.3-13.0)$ \\
\hline Body mass index, $\mathrm{kg} / \mathrm{m}^{2}, n=139$ & $16.4(13.2-20.3)$ & $16(12.5-32.7)$ \\
\hline \multicolumn{3}{|l|}{ Clinical/laboratorial involvements } \\
\hline $\begin{array}{l}\text { Persistent purpura/petechiae, } \\
n=146\end{array}$ & $6 / 27(22)$ & 25/119 (21) \\
\hline Recurrent purpura/petechiae & $7(26)$ & $20(16)$ \\
\hline $\begin{array}{l}\text { Purpura/petechiae duration, } \\
\text { days, } n=140\end{array}$ & $18.5(5-60)$ & $14(1-120)$ \\
\hline Arthritis/arthralgia & $21(78)$ & $95(77)$ \\
\hline Recurrent arthritis/arthralgia & $1(4)$ & $6(5)$ \\
\hline $\begin{array}{l}\text { Arthritis/arthralgia duration, days, } \\
n=100\end{array}$ & $4(2-13)$ & $6(1-113)$ \\
\hline Abdominal pain & $20(74)$ & $73(59)$ \\
\hline Recurrent abdominal pain, $n=149$ & $3 / 26(12)$ & 16/123 (13) \\
\hline Severe abdominal pain, $n=92$ & $7 / 20(35)$ & 26/72 (36) \\
\hline $\begin{array}{l}\text { Abdominal pain duration, } \\
\text { days, } n=83\end{array}$ & $4.5(1-40)$ & $5(1-60)$ \\
\hline Gastrointestinal bleeding, $n=149$ & $6 / 27(22)$ & 23/122 (19) \\
\hline Bowel intussusception & $0(0)$ & $1(0.8)$ \\
\hline Nephritis, $n=147$ & $10 / 27(37)$ & $56 / 120(47)$ \\
\hline Arterial hypertension, $n=122$ & 4/22 (18) & $16 / 100(16)$ \\
\hline Nephrotic syndrome, $n=147$ & $0 / 26(0)$ & $3 / 121(3)$ \\
\hline Acute kidney injury, $n=145$ & $0 / 27(0)$ & $2 / 118(2)$ \\
\hline Leukocyturia, $n=146$ & $0 / 27(0)$ & $14 / 119(12)$ \\
\hline Urinary casts, $n=146$ & $2 / 27(7)$ & $13 / 119(11)$ \\
\hline Hematuria, $n=146$ & $7 / 27(26)$ & $39 / 119(33)$ \\
\hline Proteinuria, $n=108$ & $5 / 17(29)$ & $34 / 91(37)$ \\
\hline Neuropsychiatric involvement & $0(0)$ & $1(1)$ \\
\hline Increased serum IgA, $n=76$ & 2/11 (18) & $37 / 65(57)^{*}$ \\
\hline \multicolumn{3}{|l|}{ Treatments } \\
\hline Prednisone & $25(93)$ & $60(49)^{*}$ \\
\hline Intravenous metilprednisolone & $0(0)$ & $1(1)$ \\
\hline $\begin{array}{l}\text { Prednisone dose, } \mathrm{mg} / \mathrm{kg} / \text { day, } \\
n=72\end{array}$ & $2(0.5-2)$ & $1(0.2-30)$ \\
\hline $\begin{array}{l}\text { Glucorticosteroid duration, days, } \\
n=76\end{array}$ & $47.5(7-140)$ & $37.5(1-240)$ \\
\hline Ranitidine, $n=149$ & $17 / 27(63)$ & $37 / 122(30)^{*}$ \\
\hline Ranitidine duration, days, $n=57$ & $35(2-90)$ & $60(5-425)$ \\
\hline Immunosuppressive agents & $0(0)$ & $0(0)$ \\
\hline IVIG & $1(4)$ & $1(1)$ \\
\hline
\end{tabular}

Results are presented as median (minimum value - maximum value) or $n(\%)$, increased serum $\operatorname{lgA}(>255 \mathrm{mg} / \mathrm{dL}$ ), IVIG - intravenous immunoglobulin, ${ }^{*} p$ value $<0.05$ and the other comparisons between two groups were non-significant
IgA vasculitis patients with scrotal involvement had higher frequencies of glucocorticoid and ranitidine use, with resolution of scrotal signs/symptoms. There is clinical expertise guidance for glucocorticoid treatment in this condition $[3,7]$. We suggest prompt therapy with prednisone/prednisolone (1-2 $\mathrm{mg} / \mathrm{kg} /$ day $)$ and then gradually withdrawal from two to four weeks. This management may have minimized the severity and chronicity of this manifestation.

The IgA vasculitis severity, particularly renal and gastrointestinal involvements, was similar between male and female patients $[1,22,26]$. A study from Turkey showed that renal involvement was higher in IgA vasculitis patients with scrotal involvement compared to those without this condition [22], suggesting a more severe and multisystemic disease in male patients.

Scrotal ultrasound was performed in more than 50\% of IgA vasculitis of the present study. We suggest to evaluate this exam in all male patients with IgA vasculitis to accurately diagnose scrotal involvement, excluding testicular torsion. Our IgA vasculitis patients were pre-pubertal subjects without testicular complications. In spite of that, additional evaluation of gonadal hormones, sperm and anti-sperm antibodies analysis will be necessary to assess fertility [7].

\section{Conclusion}

Scrotal involvement occurred in almost $20 \%$ of IgA vasculitis patients and was frequently evidenced as acute subtypes at diagnosis. Scrotal signs/symptoms improved after prompt glucocorticoid use and was associated with low frequency of elevated IgA serum levels.

Acknowledgements

Our gratitude to Ulysses Doria-Filho for the statistical analysis.

\section{Funding}

This study was supported by grants from Conselho Nacional de Desenvolvimento Científico e Tecnológico (CNPq 303422/2015-7 to CAS), Fundação de Amparo à Pesquisa do Estado de São Paulo (FAPESP 2015/ 03756-4 to CAS), Federico Foundation (to CAS) and by Núcleo de Apoio à Pesquisa "Saúde da Criança e do Adolescente" da USP (NAP-CriAd) to CAS.

Availability of data and materials

Not applicable.

\section{Authors' contributions}

IMB, HMA, KK, VLSM, RCG, AMES, CAS analyzed and interpreted the patient data regarding scrotal involvement in Henoch Shönlein purpura. IMB and CAS were the major contributor in writing the manuscript. All authors read and approved the final manuscript.

Ethics approval and consent to participate

This study was approved by our Ethics Committee.

Consent for publication

Not applicable.

Competing interests

The authors declare that they have no competing interests. 


\section{Publisher's Note}

Springer Nature remains neutral with regard to jurisdictional claims in published maps and institutional affiliations.

\section{Author details}

'Pediatric Rheumatology Unit, Children's Institute, Hospital das Clinicas HCFMUSP, Faculdade de Medicina, Universidade de Sao Paulo, São Paulo, Brazil. ${ }^{2}$ Universidade de Santo Amaro - UNISA, São Paulo, Brazil. ${ }^{3}$ Pediatric Rheumatology Unit, Children's Institute, Hospital das Clinicas HCFMUSP, Faculdade de Medicina, Universidade de Sao Paulo, SP, Av. Dr. Eneas Carvalho Aguiar, 647 - Cerqueira César, São Paulo, SP 05403-000, Brazil.

Received: 16 February 2018 Accepted: 18 October 2018 Published online: 03 November 2018

\section{References}

1. de Almeida JL, Campos LM, Paim LB, Leone C, Koch VH, Silva CA. Renal involvement in Henoch-Schönlein purpura: a multivariate analysis of initial prognostic factors. J Pediatr. 2007:83:259-66

2. Ozen S, Acar-Ozen NP. Recent advances in childhood vasculitis. Curr Opin Rheumatol. 2017;29:530-4.

3. Modi S, Mohan M, Jennings A. Acute scrotal swelling in HenochSchönlein purpura: case report and review of the literature. Urol Case Rep. 2016:6:9-11.

4. Júnior CR, Yamaguti R, Ribeiro AM, Melo BA, Campos LA, Silva CA. Hemorrhagic vesicle-bullous lesions in Henoch-Schönlein purpura and review of literature. Acta Reumatol Port. 2008;33:452-6.

5. Jauhola O, Ronkainen J, Koskimies O, Ala-Houhala M, Arikoski P, Hölttä T, et al. Clinical course of extrarenal symptoms in Henoch-Schönlein purpura: a 6-month prospective study. Arch Dis Child. 2010;95:871-6.

6. Suehiro RM, Soares BS, Eisencraft AP, Campos LM, Silva CA. Acute hemorrhagic edema of childhood. Turk J Pediatr. 2007;49:189-92.

7. Silva CA, Cocuzza M, Borba EF, Bonfá E. Cutting-edge issues in autoimmune orchitis. Clin Rev Allergy Immunol. 2012;42:256-63.

8. Chamberlain RS, Greenberg LW. Scrotal involvement in Henoch-Schönlein purpura: a case report and review of the literature. Pediatr Emerg Care. 1992;8:213-5.

9. Ha TS, Lee JS. Scrotal involvement in childhood Henoch-Schönlein purpura. Acta Paediatr. 2007:96:552-5.

10. Güneş M, Kaya C, Koca O, Keles MO, Karaman MI. Acute scrotum in HenochSchönlein purpura: fact or fiction? Turk J Pediatr. 2012;54:194-7.

11. Verim L, Cebeci F, Erdem MR, Somay A. Henoch-Schönlein purpura without systemic involvement beginning with acute scrotum and mimicking torsion of testis. Arch Ital Urol Androl. 2013;85:50-2.

12. Lim Y, Yi BH, Lee HK, Hong HS, Lee MH, Choi SY, et al. Henoch-Schonlein purpura: ultrasonography of scrotal and penile involvement. Ultrasonography. 2015;34:144-7.

13. Ozen S, Pistorio A, lusan SM, Bakkaloglu A, Herlin T, Brik R, et al. EULAR/ PRINTO/PRES criteria for Henoch-Schönlein purpura, childhood polyarteritis nodosa, childhood Wegener granulomatosis and childhood Takayasu arteritis: Ankara 2008. Part II: final classification criteria. Ann Rheum Dis. 2010:69:798-806

14. Rottenstreich M, Glick Y, Gofrit ON. Chronic scrotal pain in young adults. BMC Res Notes. 2017:10:241.

15. National High Blood Pressure Education Program Working Group on High Blood Pressure in Children and Adolescents. The fourth report on the diagnosis, evaluation, and treatment of high blood pressure in children and adolescents. Pediatrics. 2004;114:555-76.

16. Chan JC, Williams DM, Roth KS. Kidney failure in infants and children. Pediatr Rev. 2002;23:47-60.

17. Akcan-Arikan A, Zappitelli M, Loftis LL, Washburn KK, Jefferson LS, Goldstein SL. Modified RIFLE criteria in critically ill children with acute kidney injury. Kidney Int. 2007;71:1028-35.

18. National Kidney Foundation. K/DOQI clinical practice guidelines for chronic kidney disease: evaluation, classification, and stratification. Am J Kidney Dis. 2002;39:S1-266.

19. Pacheva IH, Ivanov IS, Stefanova K, Chepisheva E, Chochkova L, Grozeva $D$, et al. Central nervous system involvement in Henoch-Schonlein Purpura in children and adolescents. Case Rep Pediatr. 2017;2017:5483543.
20. Kiryluk K, Moldoveanu Z, Sanders JT, Eison TM, Suzuki H, Julian BA, et al. Aberrant glycosylation of $\lg A 1$ is inherited in both pediatric $\lg \mathrm{A}$ nephropathy and Henoch-Schönlein purpura nephritis. Kidney Int. 2011:80:79-87.

21. Ben-Sira L, Laor T. Severe scrotal pain in boys with Henoch-Schönlein purpura: incidence and sonography. Pediatr Radiol. 2000;30:125.

22. Tabel Y, Inanc FC, Dogan DG, Elmas AT. Clinical features of children with Henoch-Schonlein purpura: risk factors associated with renal involvement. Iran J Kidney Dis. 2012;6:269-74.

23. Kawasaki Y, Ono A, Ohara S, Suzuki Y, Suyama K, Suzuki J, et al. HenochSchönlein purpura nephritis in childhood: pathogenesis, prognostic factors and treatment. Fukushima J Med Sci. 2013;59:15-26.

24. Calvo-Río V, Loricera J, Mata C, Martín L, Ortiz-Sanjuán F, Alvarez L, et al. Henoch-Schönlein purpura in northern Spain: clinical spectrum of the disease in 417 patients from a single center. Medicine. 2014:93:106-13.

25. Zhao L, Zheng S, Ma X, Yan W. Henoch-Schönlein Purpura With Testicular Necrosis: Sonographic Findings at the Onset, During Treatment, and at Follow-up. Urology. 2017;107:223-5

26. Buscatti IM, Casella BB, Aikawa NE, Watanabe A, Farhat SCL, Campos LMA, et al. Henoch-Schönlein purpura nephritis: initial risk factors and outcomes in a Latin American tertiary center. Clin Rheumatol. 2018;37:1319-24.

Ready to submit your research? Choose BMC and benefit from:

- fast, convenient online submission

- thorough peer review by experienced researchers in your field

- rapid publication on acceptance

- support for research data, including large and complex data types

- gold Open Access which fosters wider collaboration and increased citations

- maximum visibility for your research: over $100 \mathrm{M}$ website views per year

At BMC, research is always in progress.

Learn more biomedcentral.com/submissions 